It is evident that a quantitative theory for the diffusion of silver into glass must consider that the rate of diffusion depends on the glass, the melt and the atmosphere surrounding them. Such a theory is not yet available, and more experiments are probably needed in order to solve the problem. It is reasonable to believe, however, that the diffusion coefficients of other metals into Pyrex glass are of the same order of magnitude as that of silver ${ }^{15}$. Therefore the exchange between a salt melt and a diffusion apparatus made of Pyrex glass should not be a serious problem. However, when the diffusion times are very long and when the glass surface exposed to the melt is very large (as in a fritted disc) special care should be taken.

This work has been supported by "Wilhelm och Martina Lundgrens vetenskapsfond", which is gratefully acknowledged.

\title{
Self-Diffusion in Molten Silver Nitrate
}

\author{
C.-A. SJöвlom and J. Andersson \\ Department of Physics, Chalmers University of Technology, Gothenburg, Sweden
}

(Z. Naturforschg. 21 a, 276—278 [1966] ; received 23 December 1965)

\begin{abstract}
The self-diffusion coefficient of the $\mathrm{Ag}^{+}$-ion in molten $\mathrm{AgNO}_{3}$ has been measured with the glass fibre paper strip technique in the temperature interval $220-336^{\circ} \mathrm{C}$. The result can be described by the equation

$$
D=3.2 \times 10^{-4} \exp \{-3400 /(R T)\} \mathrm{cm}^{2} \mathrm{~s}^{-1} .
$$
\end{abstract}

A comparison with the results obtained by other workers shows good agreement between the two sets of values. Possible sources of error are discussed.

Several different methods for self-diffusion measurements in molten salts have been used, e. g. different capillary methods ${ }^{1}$, the shear cell method ${ }^{2}$, and the fritted disc method ${ }^{2,3}$. Another method, the paper strip technique, has been proposed by HonIG ${ }^{4,5}$. Self-diffusion measurements in molten $\mathrm{NaNO}_{3}$, $\mathrm{KNO}_{3}$, and $\mathrm{CsNO}_{3}$ showed good agreement between the results of this method and those obtained by previous workers ${ }^{6}$. In his original paper, HonIG discussed many aspects of using the paper strip method for diffusion measurements in molten $\mathrm{AgNO}_{3}$ also, but he gave no experimental results. Since the relative merits of the different methods for diffusion measurements have been a matter of considerable discussion ${ }^{2-4,7,8}$, we found that a closer investigation of the possibilities of the paper strip technique would be valuable. We decided to use it for in-

1 J. S. Anderson and K. Saddington, J. Chem. Soc. London 1949, Suppl. p. 381. - L. E. W $W_{\text {Allin, }}$ Z. Naturforschg. 17 a, 191 [1962].

2 S. Djordjevic and G. J. Hills, Trans. Faraday Soc. 56, 269 [1960].

3 C.-A. SJöвlom and A. LundÉn, Z. Naturforschg. 18 a, 942 [1963]. - C.-A. Sлӧвцом, Z. Naturforschg. 18 a, 1247 [1963].

4 E. P. Honig, Thesis, University of Amsterdam 1964.

5 J.A. A. Ketelaar and E. P. Honig, J. Phys. Chem. 68, 1596 [1964].

${ }^{6}$ The comparison is made in ref. ${ }^{4}$, page 60 . vestigation of the self-diffusion coefficient of the $\mathrm{Ag}^{+}$. ion in molten $\mathrm{AgNO}_{3}$. Such an investigation has been performed previously by Dworkin, Escue and van Artsdalen ${ }^{9}$, using the open-ended capillary technique, and the exchange between an $\mathrm{AgNO}_{3}$ melt and a borosilicate glass has been studied recently at this laboratory ${ }^{10}$. From a comparison between the results of these two investigations and the present results, conclusions could be drawn concerning the value of the paper strip technique.

\section{Experimental}

The experimental equipment was similar to that previously used by Honig ${ }^{4}$. A strip, $15 \mathrm{~cm}$ long and $0.5 \mathrm{~cm}$ wide was cut from W h a t m a n GF 81 (GF/A) borosilicate glass fibre paper. It was impregnated with molten $\mathrm{AgNO}_{3}$ and placed on a Pyrex glass plate in a

7 S. B. Tricklebank, L. Nanis, and J. O'M. Bockris, J. Phys. Chem. 68, 58 [1964]. - J. O'M. Bockris, S. Yoshikawa, and S. R. Richards, J. Phys. Chem. 68, 1838 [1964]. L. Nanis, S. R. Richards, and J. O'M. Bockris, Rev. Sci. Instr. 36, 673 [1965].

8 P. L. Spedding and R. Mills, J. Electrochem. Soc. 112, 594 [1965].

9 A. S. Dworkin, R. B. Escue, and E. R. Van Artsdalen, J. Phys. Chem. 64, 872 [1960].

10 C.-A. Suöвlom and J. Andersson, Z. Naturforschg. 21 a, 274 [1966]. 
horizontal, wire-wound electrical furnace made from pyrophyllite ${ }^{11}$. The temperature in the furnace was kept constant to $\pm 1{ }^{\circ} \mathrm{C}$ or better with a temperature controller. The temperature of the paper strip (and the melt) was measured with a thermocouple in contact with the glass plate. The thermocouple was connected to $\mathrm{Philips}$ potentiometric recorder (measuring accuracy $\pm 0.5^{\circ} \mathrm{C}$ ).

When temperature equilibrium had been established in the furnace, the radioactive tracer, $\mathrm{Ag}^{110 \mathrm{~m}}$ (obtained from Radiochemical Centre, Amersham, England) was brought on the paper. A little bit of radioactive salt was used in the original work by Honig ${ }^{4}$, but such a technique does not lead to a true one-dimensional diffusion. In the present work, a very small paper strip, $5 \mathrm{~mm} \times 0.5 \mathrm{~mm}$, impregnated with $50 \mu \mathrm{C} \mathrm{Ag}{ }^{110 \mathrm{~m}} \mathrm{~N}_{3}$, was placed across the centre of the big paper strip. A good contact between the small paper strip and the melt was obtained by pressing gently with a pair of tweezers. After a certain time (which was very short in comparison to the diffusion time) the small paper strip was removed and the diffusion proceeded. The duration of a diffusion anneal ranged from 6 to 18 hours. The paper strip stuck to the glass plate when the salt solidified after the run, thus no correction for the volume change of the salt was needed. The radioactivity distribution on the strip was measured with a scintillation counter, equipped with an $1 \mathrm{~mm}$ wide diaphragm made of lead. The self-diffusion coefficient can be calculated from this distribution and the diffusion time in a way described elsewhere ${ }^{4}$.

In order to see if any exchange between the salt melt and the glass took place during the diffusion anneal, the radioactivity measurement was repeated when the $\mathrm{AgNO}_{3}$ had been washed away from the strip. We found a certain amount of $\mathrm{Ag}^{110 \mathrm{~m}}$ activity in the glass, the effect of which will be discussed below.

\section{Results and Discussion}

The experimental results (corrected for the influence of the glass radioactivity) are given in the table, and they can be described by the following Arrhenius" equation, obtained by "least squares" fitting ${ }^{12}$ :

$$
D=3.2 \times 10^{-4} \exp \left(-\frac{3400 \pm 320}{R T}\right)\left(\mathrm{cm}^{2} \mathrm{~s}^{-1}\right)
$$

where $R$ is expressed in cal mole $\mathrm{e}^{-1}$ degree $^{-1}$ and $T$ in degrees Kelvin.

The present value of the activation energy, $Q=$ $3.4 \mathrm{kcal} / \mathrm{mole}$, is within experimental error equal to the value obtained by Dworkin, Escue, and van Artsdalen ${ }^{9}$, using the conventional, open-ended

11 Obtained under the name of Wonderstone from $\mathrm{C}$ a r $\mathrm{te} \mathrm{r} \mathrm{s}$ (Merchants) Ltd., London.

\begin{tabular}{|c|c|}
\hline $\begin{array}{c}T \\
{ }^{\circ} \mathrm{C}\end{array}$ & $\begin{array}{c}D_{\mathrm{Ag}^{+} \times 10^{5}} \\
\mathrm{~cm}^{2} \mathrm{~s}^{-1}\end{array}$ \\
\hline 220 & 0.95 \\
236 & 1.04 \\
249 & 1.07 \\
268 & 1.21 \\
274 & 1.23 \\
278 & 1.24 \\
288 & 1.45 \\
306 & 1.43 \\
320 & 1.59 \\
336 & 1.96 \\
\hline
\end{tabular}

Table 1. Self-diffusion coefficient of the $\mathrm{Ag}^{+}$-ion in molten silver nitrate, measured with the glass fibre paper strip technique.

capillary technique ${ }^{1}$. The present $D$-values and the previous ones are in excellent agreement with each other at $220{ }^{\circ} \mathrm{C}$, and they differ slightly at $275{ }^{\circ} \mathrm{C}$. Thus the results of these two independent methods are seen to confirm each other. The reproducibility of the paper strip technique is not quite as good as that of the capillary method, if $\ln \left(D \times 10^{6}\right)$ is plotted against $10^{3} / T$, the standard deviation of the experimental points is $2.5 \%$.

The cause of the somewhat poorer reproducibility of the paper-strip method is twofold: It is very difficult to impregnate the paper strip uniformly enough. A difference in "weight per $\mathrm{cm}$ " of $3 \%$ between different parts of the strip, which is considered by Honig to be acceptable, might give rise to a difference in $D$ of about $8 \%$. Moreover, the exchange of silver between the melt and the glass affects the value of the experimental self-diffusion coefficient. After the diffusion run, about $3 \%$ of the total $\mathrm{Ag}^{110 \mathrm{~m}}$ radioactivity is found to remain in the centre of the glass fibre paper strip, cf. ref. ${ }^{4}$, page 101. The $\mathrm{Ag}^{+}$-ions react further with the glass when they have penetrated into it, which means that the remaining radioactivity inside the glass corresponds to the maximum radioactivity of the outside melt during the experiment. Thus it is found, when the final radioactivity distribution on the strip is measured, that the nearer to the maximum of the distribution curve, the larger a fraction of the measured activity is contributed by the radioactivity trapped in the glass. This effect makes the experimental selfdiffusion coefficients too low, and a mean correction of about $8 \%$ had to be applied in the present work. This was determined in the separate measurement of the radioactivity distribution in the glass. It is very difficult to obtain good counting statistics in this

12 A. HALD, Statistical Theory with Engineering Applications, John Wiley \& Sons, New York 1952, p. 522. All stated errors in this paper are standard deviations. 
measurement, which makes the correction factor rather uncertain.

The influence of end-effects ( $\Delta l$-effects) on the results of the capillary method has recently been discussed by several authors. Bockris et al. ${ }^{7}$ claim that it is impossible to avoid $\Delta l$-errors even if the flow rate past the capillary mouth is carefully chosen. According to Spedding and Mills ${ }^{8}$, on the other hand, the $\Delta l$ error will be negligible for certain flow rates. Since the investigation by Dworkin et al. was performed before the importance of these end effects was fully appreciated, it is reasonable to suspect that end errors in their capillary method might have affected their results. However, since our values and their values of $D_{\mathrm{Ag}^{+}}$in molten $\mathrm{AgNO}_{3}$ are in good agreement, we find that Dworkin et al. have succeeded in avoiding $\Delta l$ errors (at least in their measurements of $D_{\mathrm{Ag}^{+}}$.

The above results show, that the paper strip technique can be used for self-diffusion measurements in molten salts if a correction for the exchange of metal ions between the glass and the melt is applied when necessary. The glass-melt interface is very large, and this fact, in conjunction with the comparatively long diffusion times that are needed, enhances the exchange. (A somewhat similar situation is encountered in the porous frit technique ${ }^{2,3}$, but the corresponding problem is by no means so serious, since the diffusion times are of the order of 30 minutes only.) Due to the difficulty to determine the correction factor accurately, the paper strip method is not capable of the highest precision. It is, on the other hand, very simple to use, and it is able to give valuable independent checks of the results of other methods.

This work has been financially supported by "Adlerbertska Forskningsfonden", which is gratefully acknowledged. Thanks are due to Mr. W. PARKer for making the radioactive samples.

\title{
Thermoelectric Power of Molten and Solid Silver Sulphate
}

\author{
Arnold Kvist and Alar Randsalu \\ Department of Physics, Chalmers University of Technology, Gothenburg, Sweden
}

(Z. Naturforschg. 21 a, 278-281 [1966] ; received 25 August 1965)

\begin{abstract}
The thermocell $\mathrm{Ag}\left(T_{1}\right) / \mathrm{Ag}_{2} \mathrm{SO}_{4} / \mathrm{Ag}\left(T_{2}\right)$ has been studied over the temperature range 420 to $750^{\circ} \mathrm{C}$. The results can be described by the following linear relations ${ }^{1}$

$$
-\varepsilon_{1}=(0.31 \pm 0.01) \mathrm{mV} /{ }^{\circ} \mathrm{C}
$$$$
-\varepsilon=\left[(0.687+0.011)-(0.472+0.019) \cdot 10^{-3} \cdot t^{2}\right] \mathrm{mV} /{ }^{\circ} \mathrm{C} \quad\left(657-750^{\circ} \mathrm{C}\right)
$$

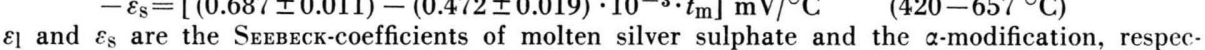
tively, and $t_{\mathrm{m}}$ is the mean temperature of the salt column in ${ }^{\circ} \mathrm{C}$.

The standard deviation of $\varepsilon_{\mathrm{s}}$ was $4.3 \cdot 10^{-3} \mathrm{mV} /{ }^{\circ} \mathrm{C}$.

The transported entropy of the silver ion and of the sulphate ion have been calculated. A discontinuous change of the emf and the transported entropies was found at the melting point.
\end{abstract}

A number of measurements of the thermoelectric power of solid and molten ionic salts has been reported ${ }^{2,3}$.

Between 412 and $657^{\circ} \mathrm{C}$ silver sulphate forms a high temperature modification with a hexagonal structure ${ }^{4}$. This modification is characterised by a high cation mobility. The electrical conductivity increases strongly at the $\beta-\alpha$ transition and the conductivity of the $\alpha$-modification is close to that of the melt. Similar high temperature modifications have been found in $\mathrm{Li}_{2} \mathrm{SO}_{4}$ and $\mathrm{K}_{2} \mathrm{SO}_{4}$.

1 All stated errors in this paper are standard deviations.

2 A.Kvist and A.LundÉn, Z. Naturforschg. 19 a, 1058 [1964] and references there.
We report here on the determination of the thermoelectric power of the system $\mathrm{Ag}\left(T_{1}\right) / \mathrm{Ag}_{2} \mathrm{SO}_{4} / \mathrm{Ag}\left(T_{2}\right)$ in the temperature range 420 to $750{ }^{\circ} \mathrm{C}$.

\section{Experimental}

Reagent grade silver sulphate (Hopkin \& Wil. liam or $\mathrm{May} \& \mathrm{Baker}$ ) has been used in all experiments without further purification. No detectable difference between the results from two lots could be found, and both lots were therefore considered to be of satisfactory purity.

3 A. Kvist, Z. Naturforschg. 19 a, 1159 [1964].

${ }^{4}$ H. A. ØYE, Acta Chem. Scand. 18, 361 [1964]; Thesis Trondheim 1963. 